Economic and Environmental Geology

Case Report

\title{
A Study on Induced effect of Aggregate and Stone Sector with Input- Output Table
}

\author{
Ji Whan Kim* \\ Center for Northern Geoscience, Korea Institute of Geoscience and Mineral Resources, Daejeon, Korea \\ *Corresponding author : kjiwhan@kigam.re.kr

\section{ARTICLE INFORMATION} \\ Manuscript received 12 October 2021 \\ Received in revised form 22 October 2021 \\ Manuscript accepted 22 October 2021 \\ Available online 29 October 2021 \\ DOI : http://dx.doi.org/10.9719/EEG.2021.54.5.573 \\ Research Highlights \\ - Analysis of industry-related inducement effects of aggregates and \\ stones \\ - Aggregate and stones has a higher employee remuneration rate \\ compared to the manufacturing industry, and higher operating \\ surplus compared to other mining industries. \\ - The induced effect of aggregate and stones showed a higher \\ power of dispersion than the sensitivity of dispersion, confirming \\ that it had a relatively backward linkage effect.
}

\begin{abstract}
This study analyzed the induced effects of the aggregate and stone sectors using the industry association table. First, the added value of the aggregate and stone sectors was summarized, and then the intermediate input structure and induced effect were analyzed. In terms of value-added structure, aggregate and stone showed a higher employee remuneration rate compared to the manufacturing industry, and a higher rate of operating surplus compared to other mining industries. The intermediate input structure summarizes the sector using aggregate and stone products as intermediate inputs and their input ratio. The proportion of the intermediate element input structure was confirmed. In addition, the main input sectors of ready-mixed concrete, the largest consumer of aggregate and stone, are also summarized.

The production-inducing effect of aggregate and stone showed a higher influence coefficient than the sensitivity coefficient, confirming that they had a relatively large rear chain effect. The production inducement effect was reviewed by reconstructing the industry association table, and it was found to show a relative superiority in the influence coefficient, similar to the results derived according to the provisional classification of the Bank of Korea.
\end{abstract}

Keywords : aggregate and stone, input-output table, induced effect, intermediate input

Citation: Kim, J.W. (2021) A Study on Induced effect of Aggregate and Stone Sector with Input-Output Table. Korea Economic and Environmental Geology, v.54, p.573-580, doi:10.9719/EEG2021.54.5.573.

This is an Open Access article distributed under the terms of the Creative Commons Attribution Non-Commercial License (http://creativecommons.org/ licenses/by-nc/3.0) which permits unrestricted non-commercial use, distribution, and reproduction in any medium, provided original work is properly cited. pISSN 1225-7281; eISSN 2288-7962/C2021 The KSEEG. Printed by Hanrimwon Publishing Company. All rights reserved. 


\section{보고}

\section{산업연관표를 이용한 골재 및 석재부문의 경제적 파급효과 분석연구}

\section{김지환 ${ }^{*}$}

한국지질자원연구원 북방지질자원전략센터

*책임저자 : kjiwhan@kigam.re.kr

\section{요 약}

본 연구는 산업연관표를 이용하여 골재 및 석재부문의 유발효과를 분석하였다. 먼저 골재 및 석재부문의 부가가치에 관해 정리 하였으며, 이어 중간투입구조와 유발효과를 분석하였다. 부가가치구조 측면에서 골재 및 석재는 제조업에 비해 높은 피용자보 수율을 보였으며, 영업잉여에 대해서도 그 외 광업에 비해 높은 비율을 보였다. 중간투입구조는 골재 및 석재 생산품을 중간투 입물로 이용하는 부문과 그 투입비율을 정리하였는데, 골재 및 석재의 배분구조와 산업부문에서 골재 및 석재를 투입하는 구조 를 정리하였으며, 레미콘, 콘크리트 제품 등 주요 수요자의 중간요소 투입구조 중 비중을 확인하였다. 아울러 골재 및 석재의 최대 수요자인 레미콘의 주요 투입부문에 대해서도 정리하였다.

골재 및 석재의 생산유발효과는 2015년 기준으로 0.774 의 값을 보인 감응도계수에 비해 0.984 의 값을 보인 영향력계수가 전체 산업에서 높은 순위를 보여 상대적으로 후방연쇄효과를 크게 갖는 것을 확인할 수 있었다. 산업연관표를 재구성하여 생산유발 효과를 검토하였는데, 한국은행의 기본부문분류에 따른 도출결과와 유사하게 영향력계수 측면에서 상대적 우위를 보이는 것으 로 나타났다.

주요어 : 골재 및 석재, 산업연관표, 유발효과, 중간투입

\section{1. 서 론}

골재자원은 국가 건설산업을 견지하는 필수 원자재이 다. 도로, 철도, 항만, 공항 등의 사회기반시설과 각종 건 물, 건축 등 국민의 생활환경 유지/조성에 요구되는 중요 자원이라 할 수 있다(Hong and Lee, 2021). 따라서 골재 자원의 수요는 주로 건설수요로부터 영향을 받게 되며, 공급계획은 건설투자 전망으로부터 영향을 받게 된다. 이 는 골재자원의 시장이 파생수요(다른 중간재 또는 최종 재화에 대한 수요의 결과로 발생하는 생산 요소 또는 중 간재에 대한 수요) 시장의 특성을 보이는 것인데, 주택공 급 및 주거개선 계획, 사회간접자본 공급계획 등 우리나 라의 최근 건설시장 여건과 골재자원 공급능력 등을 고 려할 때, 그 필요성에 비해 시장가격은 낮은 수준에 안 정되어 있다고 볼 수 있다.

한편, 2021년도 골재수급계획에 따르면 우리나라의 2020년 골재 수요는 약 236 백만 $\mathrm{m}^{3}$ 에 달하였으며, 이는 선별·파쇄 골재 및 산림 및 육상골재를 통해 약 $97 \%$ 공 급하였고 바다 및 하천 골재를 통해 약 $3 \%$ 를 공급하였 다. 또한 지역별 수요는 수도권 $41 \%$, 경상권 $26 \%$, 충청 권 $15 \%$, 전라권 $11 \%$, 제주 $2 \%$ 정도로 수도권 수요가 전 체 수요의 절반에 가까운 수요를 보였다. 동기의 건설수
주액은 각각 $51 \%, 24 \%, 12 \%, 9 \%, 4 \%$ 정도로 나타나 양 자간 비례적인 관계를 보였다.

본 연구는 산업연관표에 나타난 골재 및 석재부문과 그 외 산업간의 관계, 골재 및 석재를 투입요소로 사용하는 산업의 부가가치 및 투입비중 등을 검토하고 골재 및 석 재부문의 유발효과를 추정하는 것을 목적으로 한다.

\section{2. 산업연관표 개요}

산업연관표는 가공통계의 하나로 경제의 전체적 규모 와 구조를 반영하는 중요한 미·거시적 경제통계이며, 산 업(혹은 상품)간 연관관계를 기초로 풍부한 정보를 제공 한다. 해당 시점(연도)의 산업 생산활동에서 중간재 소비 를 중심으로 다른 산업과 갖는 관계를 제시하며, 대상산 업 자체의 직접효과와 산업간 관계에 따른 간접효과를 파악하는 데에 유용하다. 따라서 산업연관표를 이용하면 특정산업의 도입, 생산기술의 개선, 대체생산, 재활용 등 의 각종 효과를 추정·분석 할 수 있다(Choi and Kim, 2021, Kim and Kim 2021, Kim et al. 2014).

한국은행(2019)에 따르면 한 국가 경제에서 각 산업들 은 생산활동을 위해 상호간에 재화와 서비스를 구입·판 매하는 과정을 통해 직접 또는 간접적으로 서로 관계를 
맺게 되며, 산업연관표는 일정기간(보통 1년) 동안의 산 업간 거래관계를 일정한 원칙에 따라 행렬형식으로 기록 한 통계표이다. 이러한 산업연관표를 이용하여 산업간 상 호연관관계를 수량적으로 분석하는 것을 산업연관분석 (inter-industry analysis) 또는 투입산출분석(input-output analysis)이라 한다. 또한 국민소득분석이 국민경제 전체 의 활동수준을 표시하는 장점을 지녔다면, 산업연관분석 은 구조적 측면에서 산업간 연관관계를 파악할 수 있는 장점을 갖고 있다고 하였다.

산업연관표의 사용표는 각 산업별 상품의 사용내역과 부가가치, 최종수요의 항목별 사용내역에 대한 정보를 「상품×산업」행렬 형태로 나타낸 통계이다. 세로 방향으 로 보면 각 산업이 생산활동을 하기 위하여 지출한 생산 비용의 구성, 즉 투입구조를 나타낸다. 투입구조는 중간재 투입을 나타내는 중간투입부문과 임금, 이윤, 간접세 등 본원적 생산요소의 구입비용을 나타내는 부가가치부문으 로 구분되며 그 합계를 총투입액으로서 표시한다. 가로 방향으로 보면 각 상품이 어떤 상품을 생산하는 데 중간 수요 또는 최종수요의 형태로 얼마나 이용되었는가를 알 수 있는데, 이를 배분구조라고 한다. 이는 생산을 위하여 직접 투입되는 중간수요 부문과 소비재, 자본재, 수출 등 의 최종재로 판매되는 최종수요부문으로 구분되며 중간 수요액과 최종수요액의 합계를 총수요액으로서 표시한다.

산업연관표는 규모면에서 기본부문, 소분류, 중분류, 대 분류로 구분할 수 있는데, 이는 각각 381 부문, 165 부문, 83 부문, 33 부문으로 구성되어 있어 우리나라 경제의 산 업부문을 세분화한 정도가 다르다.

산업연관표를 이용하여 생산유발효과를 추정할 수 있 는데, 생산유발효과는 어떤 상품이나 서비스에 대한 최 종수요 발생이 직·간접적으로 전 산업 생산에 미치는 영 향을 말한다. 이는 각 상품부문이 재화나 서비스의 생산 에 사용하기 위해 구입한 각종 원재료, 연료 등 중간투 입물의 액수와 총투입액 간 비율행렬을 통해 측정할 수 있는 생산유발계수를 이용함으로써 추정할 수 있다.
산업연관표의 작성은 그 기초자료의 방대함으로 인해 5 년마다 실측표가 작성되며, 이를 근거로 연장표가 작성 되고 있다. 실측표는 실측조사를 바탕으로 구축된다. 따 라서 실측표에 나타난 정보가 보다 높은 정확도를 갖는 다고 할 수 있으나 연장표들을 통해 변화추이에 관한 정 보를 얻을 수 있으므로, 2015년 기준의 실측표를 중심으 로 서술을 진행하기로 한다.

본 연구는 골재 및 석재부문에 초점을 두고 있어 공표 된 산업연관표 중 381 부문으로 세분된 기본부문표를 기 초로 하되 측정오류와 이해편의를 위해 필요한 경우 소, 중, 대분류 부문구분에 따라 산업구분을 재설정하여 분 석하기로 한다.

\section{3. 골재 및 석재부문의 부가가치}

산업연관표는 중간투입 구조뿐만 아니라 부가가치 구 조에 대해서도 집계하고 있는데, 부가가치는 피용자보수, 영업잉여, 고정자본소모, 생산세(보조금 공제)로 구성된 다. 골재 및 석재 부문은 근로자 급여에 해당하는 피용 자보수의 경우 2015 년 기준 총투입액의 $16 \%$, 부가가치 의 $30 \%$ 를 차지하는 것으로 나타났다. 부가가치 총액에 서 피용자보수, 고정자본 소모, 생산세(보조금 공제)를 제 한 순 이익을 의미하는 영업잉여는 2015년 기준 총투입 액의 $26 \%$, 부가가치의 $51 \%$ 를 차지하는 것으로 나타났다. 골재 및 석재부문은 타 산업부문과 비교해 볼 때에도 높은 부가가치 비율을 보이고 있다. 타 산업과 비교하면 Table 1에 제시한 바와 같은데, 부가가치율은 제조업 평 균치를 상회하여 서비스업 평균치에 가까운 높은 값을 보였다. 영업잉여는 제조업 평균, 서비스업 평균을 넘어 높은 값을 보였으며, 피용자 보수는 제조업 평균, 서비스 업 평균에 비해 낮은 값을 보였다. 광업부문 내에서 비 교해 보면, 부가가치 비율, 영업잉여 비율은 광업평균에 비해 높으며, 피용자보수 비율은 상대적으로 낮은 것으 로 나타났다.

Table 1. Value-added summary of aggregate and stone

\begin{tabular}{cccccc}
\hline & rate of & \multicolumn{2}{c}{ compensation of employees rate } & \multicolumn{2}{c}{ net operating surplus } \\
\cline { 3 - 6 } & value-added & per value-added & per total input & per value-added & per total input \\
\hline aggregate and stone & $51.37 \%$ & $30.30 \%$ & $15.56 \%$ & $51.13 \%$ & $26.27 \%$ \\
Agricultural, forest, and fishery goods & $57.78 \%$ & $20.42 \%$ & $10.63 \%$ & $62.96 \%$ & $38.42 \%$ \\
Mined and quarried goods & $41.55 \%$ & $53.73 \%$ & $18.73 \%$ & $30.79 \%$ & $15.83 \%$ \\
Metal ores & $38.47 \%$ & $63.36 \%$ & $23.42 \%$ & $12.40 \%$ & $4.60 \%$ \\
Non-metallic mineral mining & $51.32 \%$ & $37.31 \%$ & $17.12 \%$ & $47.43 \%$ & $26.51 \%$ \\
Manufacturing & $27.37 \%$ & $42.07 \%$ & $11.21 \%$ & $29.88 \%$ & $8.81 \%$ \\
Service & $54.27 \%$ & $52.68 \%$ & $29.01 \%$ & $22.28 \%$ & $12.09 \%$ \\
\hline
\end{tabular}




\section{4. 골재 및 석재부문의 중간투입 구조}

산업연관표 기본부문표는 381 개 부문분류를 설정한 정 보를 제공하고 있는데, 골재 및 석재 부문을 구분해 제 시하고 있다. 이에 따르면 골재 및 석재를 중간투입물로 사용하고 있는 부문은 56 개 부문이며, 2015년 기준 총 2 조 3,450 억원 규모의 중간수요와 582 억원 규모의 최종수 요자의 수요를 보였다.

중간투입으로 골재 및 석재를 사용하는 주요 부문은 레 미콘, 콘크리트제품, 아스콘 및 아스팔트 제품, 주거용 건 물, 도로시설, 건축보수 등이 있다. 중간투입 중 골재 및 석재의 비중을 기준으로 보면 레미콘, 콘크리트 제품, 가 정용 도자기, 석제품, 아스콘 및 아스팔트 제품 순으로 나타났으며, 골재 및 석재의 중간투입액을 기준으로 보 면 레미콘, 콘크리트 제품, 아스콘 및 아스팔트 제품, 주 거용 건물, 도로시설 순으로 나타났다. 산업연관표 기본 부문표에 따른 부문순위와 비율은 다음 Table 2,3 과 같다.

Table 2는 골재 및 석재가 많이 투입되는 산업에 대해 산업별로 총 골재 및 석재가 배분되는 비율을 2015년 기 준의 순위에 따라 정리한 것이다. 상위 20 개 산업에 골 재 및 석재 총생산액의 $99 \%$ 가 배분, 투입되었다. 가장 많은 투입, 즉, 중간수요를 보인 것은 레미콘으로 전체
골재 및 석재 생산액의 $74 \%$ 가량을 수요하였으며, 콘크 리트 제품이 $10 \%$ 를 수요하여 이 두 부문에서 전체 생산 액의 $84 \%$ 를 이용한 것으로 나타났다. 이어 아스콘 및 아 스팔트 제품, 주거용 건물, 도로시설, 건축보수, 비주거용 건물, 항만시설, 석제품 등에 $1 \%$ 대 중간수요가 나타났 으며, 철도시설, 도시토목, 가정용 도자기, 기초무기화합 물, 폐기물 수집 운반 및 처리, 제조임가공서비스, 하천 사방, 사업시설 유지관리 및 조경서비스, 기타 비금속광 물 제품, 금속주물, 산업플랜트 등에 $1 \%$ 미만의 중간수 요가 나타났다.

한편, 골재 및 석재의 중간수요, 즉 특정 산업의 골재 및 석재에 대한 중간투입 비중이 높은 순으로 정리한 것 은 Table 3에 정리하였다. 레미콘은 레미콘을 생산하기 위해 다양한 다른 중간투입요소 즉, 생산요소를 투입하 는데, 그 중 골재 및 석재는 2015년 기준으로 약 $21 \%$ 를 차지하여 골재 및 석재를 중간투입으로 사용하는 부문 중 가장 높은 비중을 보인 부문이다. 콘크리트 제품은 $7 \%$, 가정용 도자기는 $5 \%$, 석제품, 아스콘 및 아스팔트 제품, 항만시설은 $2 \%$ 를 상회하는 비중을 보인 부문이다. Table 2, 3을 통해서 레미콘, 콘크리트 제품, 아스콘 및 아스팔트는 골재 및 석재의 주 수요자이며, 골재 및 석 재를 사용하는 부문 중 높은 의존도를 보이는 부문임을

Table 2. Aggregate and stone intermediate demand rank by quantity for major industries

\begin{tabular}{|c|c|c|c|c|}
\hline rank & code & sector name & $\begin{array}{l}\text { aggregate and stone input } \\
\text { (mil. KRW) }\end{array}$ & $\begin{array}{l}\text { aggregate and stone } \\
\text { input rate(money)* }\end{array}$ \\
\hline 1 & 2631 & Ready-mixed concrete & $1,727,652$ & $73.67 \%$ \\
\hline 2 & 2632 & Concrete product & 234,917 & $10.02 \%$ \\
\hline 3 & 2694 & Ascon and asphalt products & 43,183 & $1.84 \%$ \\
\hline 4 & 5010 & Constructions of residential buildings & 40,908 & $1.74 \%$ \\
\hline 5 & 5111 & Constructions of facilities for road traffic & 40,605 & $1.73 \%$ \\
\hline 6 & 5030 & Building repair & 34,946 & $1.49 \%$ \\
\hline 7 & 5020 & Constructions of non-residential buildings & 34,891 & $1.49 \%$ \\
\hline 8 & 5113 & Port facilities & 24,379 & $1.04 \%$ \\
\hline 9 & 2692 & Stone product & 24,003 & $1.02 \%$ \\
\hline 10 & 5112 & Railroad facilities & 21,551 & $0.92 \%$ \\
\hline 11 & 5124 & Constructions of urban facilities & 17,557 & $0.75 \%$ \\
\hline 12 & 2611 & Home ceramic & 17,400 & $0.74 \%$ \\
\hline 13 & 1722 & Basic inorganic chemical products & 17,009 & $0.73 \%$ \\
\hline 14 & 4912 & Waste Collection, Transport and Treatment (Industry) & 13,681 & $0.58 \%$ \\
\hline 15 & 4401 & Manufacturing services and repair services of industrial equipment & 7,022 & $0.30 \%$ \\
\hline 16 & 5121 & River erosion control & 5,905 & $0.25 \%$ \\
\hline 17 & 7410 & Landscaping, maintenance services for business facilities & 4,930 & $0.21 \%$ \\
\hline 18 & 2699 & Other non-metallic mineral products & 4,813 & $0.21 \%$ \\
\hline 19 & 2900 & Metal foundries & 4,707 & $0.20 \%$ \\
\hline 20 & 5134 & Constructions of industrial plants for manufacturing & 3,924 & $0.17 \%$ \\
\hline
\end{tabular}


Table 3. Aggregate and stone intermediate demand rank by input rate for major industries

\begin{tabular}{|c|c|c|c|c|}
\hline rank & code & sector name & $\begin{array}{l}\text { aggregate and stone input } \\
\text { (mil. KRW) }\end{array}$ & $\begin{array}{l}\text { aggregate and stone input } \\
\text { rate(money)* }\end{array}$ \\
\hline 1 & 2631 & Ready-mixed concrete & $1,727,652$ & $20.88 \%$ \\
\hline 2 & 2632 & Concrete product & 234,917 & $6.79 \%$ \\
\hline 3 & 2611 & Home ceramic & 17,400 & $4.68 \%$ \\
\hline 4 & 2692 & Stone product & 24,003 & $2.71 \%$ \\
\hline 5 & 2694 & Ascon and asphalt products & 43,183 & $2.40 \%$ \\
\hline 6 & 5113 & Port facilities & 24,379 & $2.36 \%$ \\
\hline 7 & 5112 & Railroad facilities & 21,551 & $0.53 \%$ \\
\hline 8 & 5030 & Building repair & 34,946 & $0.51 \%$ \\
\hline 9 & 5121 & River erosion control & 5,905 & $0.49 \%$ \\
\hline 10 & 4912 & Waste Collection, Transport and Treatment (Industry) & 13,681 & $0.47 \%$ \\
\hline 11 & 5111 & Constructions of facilities for road traffic & 40,605 & $0.44 \%$ \\
\hline 12 & 2699 & Other non-metallic mineral products & 4,813 & $0.42 \%$ \\
\hline 13 & 1722 & Basic inorganic chemical products & 17,009 & $0.36 \%$ \\
\hline 14 & 5124 & Constructions of urban facilities & 17,557 & $0.35 \%$ \\
\hline 15 & 2614 & Non-refractory ceramic wares for construction & 882 & $0.19 \%$ \\
\hline 16 & 5122 & Constructions of water and sewage facilities & 3,915 & $0.18 \%$ \\
\hline 17 & 7410 & Landscaping, maintenance services for business facilities & 4,930 & $0.14 \%$ \\
\hline 18 & 5131 & Constructions of environmental purification facility & 1,756 & $0.12 \%$ \\
\hline 19 & 2900 & Metal foundries & 4,707 & $0.11 \%$ \\
\hline 20 & 5010 & Constructions of residential buildings & 40,908 & $0.10 \%$ \\
\hline
\end{tabular}

*aggregate and stone input / intermediate demand, money base

확인할 수 있다. 특히 레미콘 생산요소로서 약 $32 \%$ 를 차 지하는 시멘트 다음으로 높은 비중인 $21 \%$ 를 차지하여 레미콘 생산의 필수 생산요소로서 의의를 확인할 수 있다.

골재 및 석재를 가장 많이 수요한 레미콘은 Table 4에 정리한 바와 같이 주거용 건물, 비주거용 건물, 도로시설, 철도시설, 도시토목 등에서 중간투입물로 수요되고 있는 것으로 나타났다.

레미콘은 주 수요부문 상위 10 개에서 전체의 $92 \%$ 전
후의 수요를 보이는데, 건물과 도로시설이 $80 \%$ 정도의 점유를 보이는 것으로 나타났다. 레미콘을 사용하는 주 요 부문에서 중간투입 중 레미콘 비중 순위는 도로시설, 주거용 건물, 철도시설, 비주거용 건물, 도시토목 순으로 나타났는데, 각각의 비중 추이는 Table 5에 정리하였다.

도로시설은 도로시설 생산을 위해 다양한 생산요소를 투입하는데, 그 중 레미콘의 비중은 2015년 기준으로 약 $12 \%$ 를 넘는 것으로 나타났다.

Table 4. Major industries intermediate demand rank by input rate for ready-mixed concrete

\begin{tabular}{|c|c|c|c|c|c|c|c|}
\hline rank & code & sector name & 2015 & 2016 & 2017 & 2018 & 2019 \\
\hline 1 & 5010 & Constructions of residential buildings & $39.06 \%$ & $42.61 \%$ & $45.87 \%$ & $45.21 \%$ & $41.87 \%$ \\
\hline 2 & 5020 & Constructions of non-residential buildings & $29.90 \%$ & $29.42 \%$ & $29.90 \%$ & $29.91 \%$ & $32.05 \%$ \\
\hline 3 & 5111 & Constructions of facilities for road traffic & $10.49 \%$ & $9.88 \%$ & $8.00 \%$ & $7.18 \%$ & $8.11 \%$ \\
\hline 4 & 5112 & Railroad facilities & $3.38 \%$ & $2.61 \%$ & $2.23 \%$ & $2.47 \%$ & $2.24 \%$ \\
\hline 5 & 5124 & Constructions of urban facilities & $3.28 \%$ & $2.99 \%$ & $2.68 \%$ & $2.72 \%$ & $2.86 \%$ \\
\hline 6 & 5030 & Building repair & $2.20 \%$ & $2.17 \%$ & $1.98 \%$ & $2.21 \%$ & $2.32 \%$ \\
\hline 7 & 5134 & Constructions of industrial plants for manufacturing & $1.14 \%$ & $0.89 \%$ & $0.83 \%$ & $0.92 \%$ & $0.92 \%$ \\
\hline 8 & 5121 & River erosion control & $0.78 \%$ & $0.77 \%$ & $0.59 \%$ & $0.62 \%$ & $0.70 \%$ \\
\hline 9 & 2632 & Concrete product & $0.73 \%$ & $0.71 \%$ & $0.67 \%$ & $0.70 \%$ & $0.67 \%$ \\
\hline 10 & 5113 & Port facilities & $0.57 \%$ & $0.49 \%$ & $0.41 \%$ & $0.49 \%$ & $0.53 \%$ \\
\hline
\end{tabular}


Table 5. Major industries intermediate demand rate of ready-mixed concrete

\begin{tabular}{|c|c|c|c|c|c|c|}
\hline code & sector name & 2015 & 2016 & 2017 & 2018 & 2019 \\
\hline 2632 & Concrete product & $2.23 \%$ & $2.26 \%$ & $2.14 \%$ & $2.20 \%$ & $2.14 \%$ \\
\hline 5010 & Constructions of residential buildings & $10.28 \%$ & $10.56 \%$ & $10.09 \%$ & $9.98 \%$ & $9.71 \%$ \\
\hline 5020 & Constructions of non-residential buildings & $7.44 \%$ & $7.62 \%$ & $7.27 \%$ & $7.21 \%$ & $7.01 \%$ \\
\hline 5030 & Building repair & $3.37 \%$ & $3.40 \%$ & $3.19 \%$ & $3.21 \%$ & $3.15 \%$ \\
\hline 5111 & Constructions of facilities for road traffic & $12.01 \%$ & $12.63 \%$ & $11.75 \%$ & $11.32 \%$ & $10.82 \%$ \\
\hline 5112 & Railroad facilities & $8.76 \%$ & $8.74 \%$ & $8.13 \%$ & $8.08 \%$ & $7.60 \%$ \\
\hline 5113 & Port facilities & $5.87 \%$ & $6.02 \%$ & $5.75 \%$ & $5.69 \%$ & $5.46 \%$ \\
\hline 5121 & River erosion control & $6.89 \%$ & $6.87 \%$ & $6.52 \%$ & $6.51 \%$ & $6.31 \%$ \\
\hline 5124 & Constructions of urban facilities & $6.87 \%$ & $7.20 \%$ & $6.57 \%$ & $6.36 \%$ & $6.18 \%$ \\
\hline 5134 & Constructions of industrial plants for manufacturing & $2.10 \%$ & $2.15 \%$ & $1.99 \%$ & $2.01 \%$ & $1.86 \%$ \\
\hline
\end{tabular}

\section{5. 골재 및 석재부문의 유발효과 추정}

산업연관표는 부문 간 투입구조와 배분구조를 표현하 고 있어 생산유발효과를 분석할 수 있는데, 목적에 따라 조정된 산업연관표로부터 투입계수를 도출하여 재화나 서비스에 대한 최종수요가 발생하였을 때 각 부문으로 파급되는 생산유발효과의 크기를 계측할 수 있다. 최종 수요와 투입구조가 알려진 상태에서의 연립방정식 체계 를 통해 개별부문에 대한 파급효과를 무한급수 형태로 파악할 수 있다. 한국은행(2019)의 도식을 인용하면, 다 음과 같다.

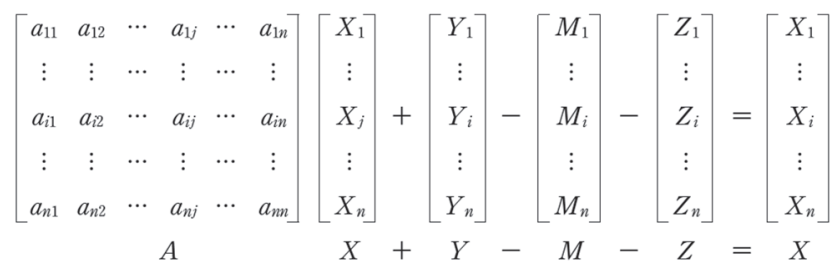

이 때, $A$ 는 투입계수행렬, $X$ 는 총산출액 벡터, $Y$ 는 최 종수요액 벡터, $M$ 은 수입액 벡터 그리고 $Z$ 는 잔폐물발 생액 벡터를 나타낸다. 이 행렬식을 단위행렬 $I$ 를 이용해 $X$ 에 관해서 풀면 다음과 같고 $(I-A)^{-1}$ 를 생산유발계수행 렬 혹은 Leontief 역행렬이라 한다.

$$
\begin{aligned}
X-A X & =Y-M-Z \\
(I-A) X & =Y-M-Z \\
X & =(I-A)^{-1}(Y-M-Z)
\end{aligned}
$$

이와 같은 방식으로 투입계수를 이용하여 생산유발계 수를 계산하면 최종수요의 변화를 독립적으로 추정하여 이에 대응하는 생산의 변화 수준을 측정할 수 있는데, 1 단위의 최종수요가 주어지는 경우 각 부문의 생산에 미 치는 직접적, 간접적 파급효과를 나타내며 누적승수의 의 미를 갖고 있다.
이렇게 도출된 생산유발계수는 영향력 계수와 감응도 계수로 구성되는데, 영향력계수는 어떤 산업의 생산물에 대한 최종수요가 1 단위 발생하였을 경우 전 산업에서 생 산해야 하는 크기를 전 산업 평균에 대한 상대적 크기로 나타낸 것으로, 어느 산업의 생산에 다른 산업의 생산물 이 중간재로 많이 사용되는 경우에는 영향력계수가 높아 지며 후방연쇄효과가 크다고 표현한다. 감응도계수는 모 든 산업의 생산물에 대하여 각각 1 단위씩의 최종수요가 발생하였을 경우 어떤 산업에서 생산해야 하는 크기를 전 산업 평균에 대한 상대적인 크기로 나타낸 것인데, 어 떤 산업의 생산물이 다른 산업의 생산에 중간재로 많이 사용되는 경우에는 감응도계수가 높아져 전방연쇄효과가 크다고 표현한다. 아울러 최종수요발생에 의해 생산이 유 발되고 이 과정에서 부가가치도 창출되기 때문에 최종수 요의 발생과의 관계를 통해 부가가치유발효과도 산출할 수 있다.

Table 6은 381개 부문분류에 따른 생산유발계수와 부 가가치유발계수를 요약 제시하였다. 전방연쇄효과를 나 타내는 감응도계수는 2015-2019년 기간에 0.708 내외의 값을 보였으며, 후방연쇄효과를 나타내는 영향력계수는 동기간에 대해 1.005 내외의 값을 보였다. 전산업 평균을 1 로 단위화한 두 계수는 각각 전체 381 개 부문에서 220 위, 195 위 수준의 순위를 나타내는 것으로 중위권 유발 계수를 갖는다고 할 수 있다.

부가가치유발은 최종수요에 따르므로 이를 제외한 생 산유발효과를 부문분류를 조정한 산업연관표를 이용해 재추정할 수 있다. 이는 부문분류 기준에 따른 효과를 조 정하는 의미가 있으며, 본 연구에서는 81 개 부문으로 조 정한 산업연관표를 구축하고 이를 통해 도출되는 생산유 발효과를 추가적으로 제시한다. 산업연관표 재분류는 한 국은행의 부문분류체계를 원용하되 관심 있는 부문에 대 해서는 기본부문의 구분을 따르는 방법으로 진행하였다. 
Table 6. Summary of induced effect coefficients of aggregate and stone

\begin{tabular}{|c|c|c|c|c|c|c|}
\hline & & 2015 & 2016 & 2017 & 2018 & 2019 \\
\hline \multirow{3}{*}{ Sensitivity of dispersion } & aggregate and stone & 0.775 & 0.766 & 0.754 & 0.520 & 0.724 \\
\hline & no. of sector & & & 381 & & \\
\hline & rank & 182 & 190 & 187 & 341 & 200 \\
\hline \multirow{3}{*}{ Power of dispersion } & aggregate and stone & 0.984 & 0.989 & 0.996 & 1.029 & 1.025 \\
\hline & no. of sector & & & 381 & & \\
\hline & rank & 209 & 206 & 198 & 180 & 180 \\
\hline \multirow{3}{*}{$\begin{array}{l}\text { Total value-added inducement } \\
\text { coefficientt }\end{array}$} & aggregate and stone & 0.907 & 0.898 & 0.886 & 0.869 & 0.877 \\
\hline & total average & 0.747 & 0.737 & 0.722 & 0.712 & 0.717 \\
\hline & rank & 89 & 118 & 60 & 74 & 66 \\
\hline
\end{tabular}

Table 7-1. Power of dispersion for rearranged table

\begin{tabular}{ccccccccccc}
\hline \multirow{2}{*}{ Power of dispersion } & \multicolumn{2}{c}{2015} & \multicolumn{2}{c}{2016} & \multicolumn{2}{c}{2017} & \multicolumn{2}{c}{2018} & \multicolumn{2}{c}{2019} \\
\cline { 2 - 11 } & \multicolumn{2}{c}{ coef. (rank) } & \multicolumn{2}{c}{ coef. (rank) } & \multicolumn{2}{c}{ coef. (rank) } & \multicolumn{2}{c}{ coef. (rank) } & coef. (rank) \\
\hline aggregate and stone & 0.844 & $(67)$ & 0.846 & $(66)$ & 0.838 & $(67)$ & 0.864 & $(65)$ & 0.861 & $(64)$ \\
limestone & 0.710 & $(75)$ & 0.713 & $(74)$ & 0.685 & $(75)$ & 0.751 & $(73)$ & 0.761 & $(73)$ \\
Other non-metallic mineral products & 0.967 & $(49)$ & 0.953 & $(53)$ & 0.961 & $(50)$ & 0.976 & $(48)$ & 1.130 & $(21)$ \\
cement & 1.082 & $(30)$ & 1.085 & $(30)$ & 1.115 & $(24)$ & 1.156 & $(15)$ & 1.146 & $(16)$ \\
ready-mixed concrete & 1.141 & $(17)$ & 1.141 & $(18)$ & 1.135 & $(21)$ & 1.148 & $(17)$ & 1.137 & $(19)$ \\
Concrete product & 1.106 & $(26)$ & 1.108 & $(24)$ & 1.112 & $(26)$ & 1.123 & $(24)$ & 1.093 & $(31)$ \\
Ascon and asphalt products & 1.195 & $(12)$ & 1.193 & $(8)$ & 1.218 & $(9)$ & 1.245 & $(8)$ & 1.179 & $(13)$ \\
\hline
\end{tabular}

Table 7-2. Sensitivity of dispersion for rearranged table

\begin{tabular}{cccccccccccc}
\hline \multirow{2}{*}{ Sensitivity of dispersion } & \multicolumn{2}{c}{2015} & \multicolumn{2}{c}{2016} & \multicolumn{2}{c}{2017} & \multicolumn{2}{c}{2018} & \multicolumn{2}{c}{2019} \\
\cline { 2 - 11 } & \multicolumn{2}{c}{ coef. (rank) } & \multicolumn{2}{c}{ coef. (rank) } & \multicolumn{2}{c}{ coef. (rank) } & \multicolumn{2}{c}{ coef. (rank) } & coef. (rank) \\
\hline aggregate and stone & 0.548 & $(48)$ & 0.564 & $(47)$ & 0.538 & $(49)$ & 0.517 & $(51)$ & 0.516 & $(53)$ \\
limestone & 0.582 & $(43)$ & 0.621 & $(39)$ & 0.583 & $(41)$ & 0.566 & $(41)$ & 0.586 & $(39)$ \\
Othernon-metallic mineral products & 0.515 & $(55)$ & 0.533 & $(52)$ & 0.505 & $(54)$ & 0.509 & $(53)$ & 0.527 & $(49)$ \\
cement & 0.698 & $(33)$ & 0.687 & $(36)$ & 0.651 & $(35)$ & 0.610 & $(37)$ & 0.591 & $(38)$ \\
ready-mixed concrete & 0.553 & $(46)$ & 0.569 & $(46)$ & 0.539 & $(48)$ & 0.527 & $(48)$ & 0.526 & $(50)$ \\
Concrete product & 0.590 & $(41)$ & 0.614 & $(40)$ & 0.587 & $(40)$ & 0.572 & $(40)$ & 0.571 & $(42)$ \\
Ascon and asphalt products & 0.461 & $(58)$ & 0.458 & $(59)$ & 0.458 & $(57)$ & 0.456 & $(57)$ & 0.460 & $(57)$ \\
\hline
\end{tabular}

따라서 한국은행 부문분류 체계의 농림수산과 서비스업 부문에 대해 대분류 기준을 따랐으며, 비금속광물, 기타 비금속광물제품과 토목건설에 대해 기본부문 분류 기준 을, 그 외에 대해서 중분류 기준을 따라 조정하였다. 주 요 관련부문인 골재 및 석재, 석회석, 기타비금속광물, 레 미콘의 산출결과는 다음 Table 7에 제시하였다.

한국은행이 비금속광물 분류에 포함한 골재 및 석재, 석회석, 기타비금속광물과 이들을 주원료로 투입하는 시 멘트, 레미콘, 콘크리트제품, 아스콘 및 아스팔트제품의 영향력계수와 감응도계수를 정리하였다. 후방연쇄효과를
의미하는 영향력계수의 경우 골재 및 석재는 기간 평균 약 0.851 로 석회석보다 높고, 기타비금속광물보다는 낮 은 값을 보였으며, 골재 및 석재를 가장 많이 투입하는 레미콘과 아스콘 및 아스팔트 제품은 각각 1.140 과 1.206 의 값을 보여 높은 순위를 보였다. 전방연쇄효과를 의미 하는 감응도계수의 경우 골재 및 석재는 기간 평균 0.516 으로 기타비금속광물보다 높고 석회석보다 낮은 값을 보 였으며, 레미콘과 아스콘 및 아스팔트 제품은 각각 0.543 과 0.459 의 값을 보여 시멘트와 콘크리트 제품에 비해 낮 은 값을 보였다. 


\section{6. 결 론}

본 연구는 산업연관표를 이용하여 골재 및 석재부문의 유발효과를 분석하였다. 먼저 골재 및 석재부문의 부가 가치에 관해 정리하였으며, 이어 중간투입구조와 유발효 과를 분석하였다. 부가가치구조 측면에서 골재 및 석재 는 제조업에 비해 높은 피용자보수율을 보였으며, 영업 잉여에 대해서도 그 외 광업에 비해 높은 비율을 보였다. 중간투입구조는 골재 및 석재 생산품을 중간투입물로 이 용하는 부문과 그 투입비율을 정리하였는데, 골재 및 석 재의 배분구조와 산업부문에서 골재 및 석재를 투입하는 구조를 정리하였으며, 레미콘, 콘크리트 제품 등 주요 수 요자의 중간요소 투입구조 중 비중을 확인하였다. 아울 러 골재 및 석재의 최대 수요자인 레미콘의 주요 투입부 문에 대해서도 정리하였다.

골재 및 석재의 생산유발효과는 감응도계수에 비해 영 향력계수가 높은 순위를 보여 상대적으로 후방연쇄효과 를 크게 갖는 것을 확인할 수 있었다. 산업연관표를 재 구성하여 생산유발효과를 검토하였는데, 한국은행의 기 본부문분류에 따른 도출결과와 유사하게 영향력계수 측 면에서 상대적 우위를 보이는 것으로 나타났다.

\section{사 사}

이 연구는 한국지질자원연구원에서 수행하고 있는 국 토교통부 “2021년 골재자원조사 및 관리사업(IP2021-006)" 의 지원으로 수행되었습니다. 또한 논문에 대한 세심한 검토와 제안을 해주신 심사위원 분들께 감사드립니다.

\section{References}

Bank of Korea (2019) 2015 Input-Output Statistics, BOK webpage, http://ecos.bok.or.kr/

Choi, J.H. and Kim, J.W. (2021) Estimation of Economic Inducement Effect of Urban Mining Upon Applying Laser Induced Breakdown Spectroscopy Technology. Jour. Korean Soc. Miner. Energy Resour. Eng., v.58, p.300-306. doi: 10.32390/ ksmer.2021.58.4.300

Hong, S.S. and Lee, J.Y. (2021) Analysis of Domestic Aggregate Production of Korea in 2019 (II) - by Local Governments. Econ. Environ. Geol., v.54, p.427-439. doi: 10.9719/EEG.2021.54.4.427

Kim, J.W., Lee, K.H. and Kim. Y.K. (2014) A Study on Estimation of Economic Effects on Mining Products Import Substitution Using Macroeconometric Input-Output Model. Econ. Environ. Geol., v.47, p.237-246. doi: 10.9719/EEG.2014.47.3.237

Kim, J.W, and Kim. Y.K. (2021) Induced Effects of Environmentally Friendly Generations in Korea. Sustainability, v.13, 4404. doi: $10.3390 /$ su13084404 